\title{
Anomalous Variations in the Thermohaline Structure of the Arctic Ocean
}

\author{
I. E. Frolov ${ }^{a}$, I. M. Ashik ${ }^{a}$, H. Kassens ${ }^{b}$, I. V. Polyakov ${ }^{c}$, A. Yu. Proshutinsky ${ }^{d}$, \\ V. T. Sokolov ${ }^{a}$, and L. A. Timokhov ${ }^{a}$ \\ Presented by Academician A.P. Lisitsyn March 12, 2009
}

Received March 12, 2009

DOI: $10.1134 / \mathrm{S} 1028334 \mathrm{X} 09090323$

In the last two decades, significant changes have occurred in the Arctic Ocean as well as in the entire Arctic region. The ice cover of Arctic seas, which was gradually (linearly) decreasing from the beginning of the 20th century to the end of it [1], began to shrink rapidly in the 1990s and in the 21st century [2]. Salinity variations in the upper layer changed sign in different regions [3]. The temperature of Atlantic waters in the Arctic basin started to increase. At the end of the 1990s, stabilization of Atlantic water transport to the Arctic Basin was observed [4], but starting from 2004, the temperature of Atlantic waters in the Eurasian subbasin increased even more and reached values that had not been observed here previously [5]. In 2007, extreme summer processes in the Arctic that followed this increase and anomalous state of the ice cover and upper layer of the ocean that were formed by the beginning of autumn put forward a pressing problem to evaluate the variation in the thermohaline structure of the Arctic Ocean as a whole.

The observations during expeditions of the Arctic and Antarctic Research Institute, Russian-American (AVLAP/NABOS-2007), and Russian-German (BARKALAV-2008/TRANSDRIFT-XII) expeditions, drifting oceanographic buoys ITP, and others made possible to collect a large amount of oceanographic data, which allows us to form a sufficiently complete concept about the unique processes in 2007 [2]. It is worth noting that field investigations were part of the

\footnotetext{
${ }^{a}$ Arctic and Antarctic Research Institute, ul. Beringa 38, St. Petersburg, 199397 Russia e-mail:ashik@aari.nw.ru

${ }^{b}$ Leibniz-Institut für Meereswissenschaften, IFM-GEOMAR Gebaeude Ostufer, Wischhofstr. 1-3, Geb. 4, Kiel, D-24148 Germany

${ }^{c}$ International Arctic Research Center, P.O. Box 757335, Fairbanks, Alaska, 99775 USA

${ }^{d}$ Woods Hole Oceanographic Institution, Woods Hole, Massachusetts, 02543 USA
}

vast program of the International Polar Year (IPY) in 2007-2008.

Analysis of the data of observations demonstrated the following. In the summer of 2007, extremely high temperatures were observed in the upper layer of the American-Asian subbasin, and high positive anomalies were formed, which reached $+3^{\circ} \mathrm{C}$. The area occupied by waters with temperatures greater than $-1^{\circ} \mathrm{C}$ was almost two times greater than the climatic one. In the central part of the Eurasian subbasin, the water temperature in the surface layer was close to the climatic value. Anomalies were within -0.5 to $+0.5^{\circ} \mathrm{C}$. However, in the northern parts of the Barents and Kara seas, the temperature of the upper layer was greater than the climatic mean value with anomalies up to $+2^{\circ} \mathrm{C}$; in the eastern part of the Laptev Sea, positive anomalies were within +2 to $+5^{\circ} \mathrm{C}$ in the layer of 5-10 $\mathrm{m}$.

The structure of surface salinity distributions is distinguished by the existence of a few extreme values. In summer 2007, anomalous freshening was observed in the surface layer in the American-Asian subbasin. Two large regions of high negative anomalies were also found (freshening of the surface layer) from -4 to $-6 \%$. The first region was located in the southern part of the Podvodnikov Basin and adjacent part of the Siberian shelf with the center at $80^{\circ} \mathrm{N}, 160^{\circ} \mathrm{E}$. The second was located in the Canadian Basin. Strong salination was found in the upper layer of the central part of the Eurasian subbasin. Positive anomalies reached $2 \%$, while in the central part of the Laptev Sea, anomalies were as high as $+6 \%$. At the same time, in the northern parts of the Barents and Kara seas, a slight freshening was observed with anomalies on the order of $-1 \%$.

Atmospheric circulation forcing was one of the main causes of such structure of surface thermohaline fields. Beginning from the spring, winds of the southern component dominated in the region, and high positive anomalies of air temperature were observed, which reached $+8^{\circ} \mathrm{C}$ in August [2]. Heat fluxes and wind forcing caused intense melting, breaking of ice, and rapid retreat of the ice edge to the north. In the 

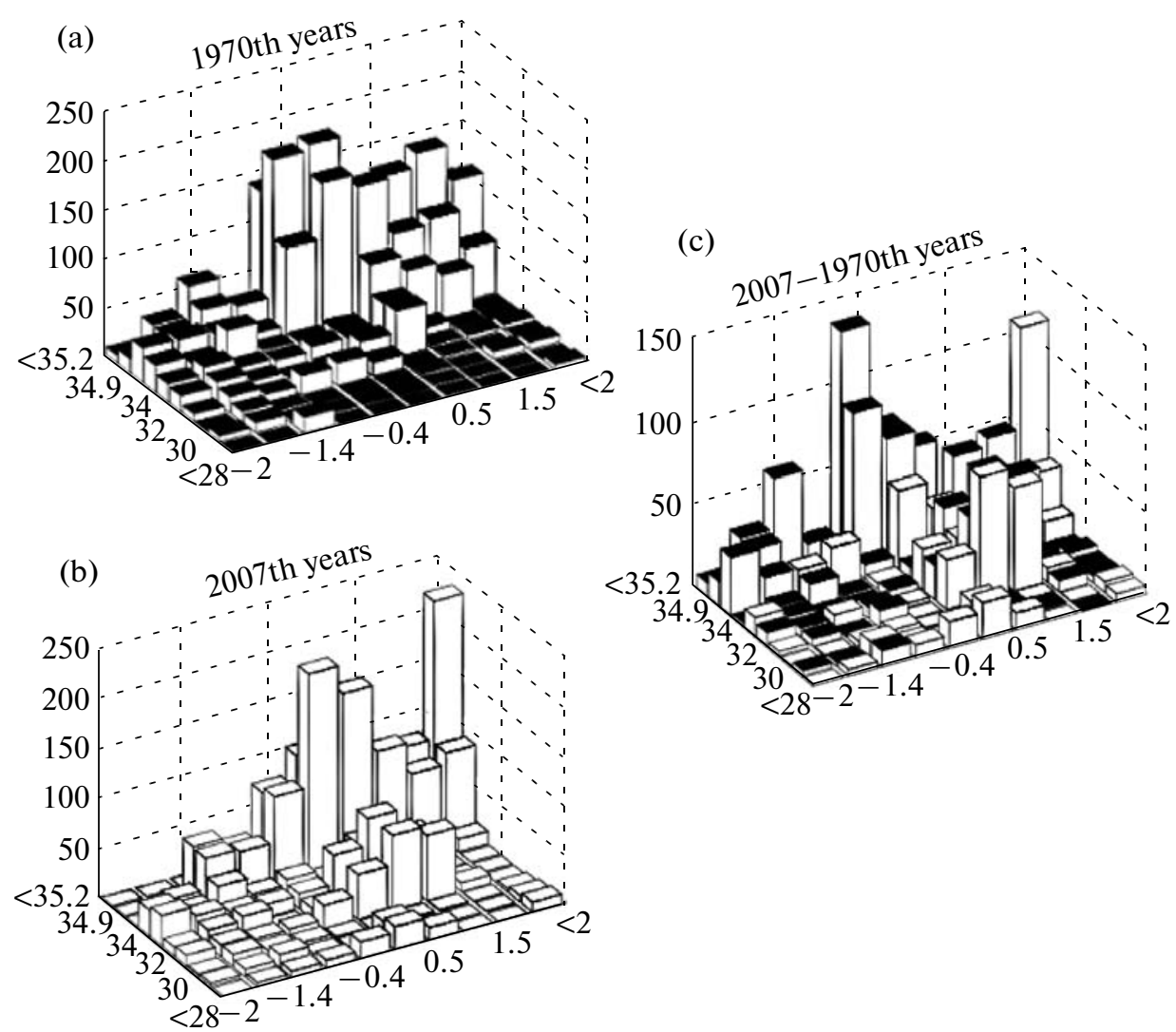

Fig. 1. Histograms of Arctic Ocean water volumes (water volume in meters per unit square is laid off as the ordinate) within the specific ranges of temperature and salinity (horizontal axes) for the summer seasons of 1970-1979 (a) and 2007 (b); histogram of the difference between water volumes in 2007 and 1970-1979.

Pacific part of the Arctic Ocean, a large territory, which was previously covered with drifting ice, became ice-free. At the end of September, the boundary of the ice cover displaced far to the north reaching in some places the latitude of $87^{\circ}$. Formation of a large ice-free water basin facilitated sufficient warming of the upper water layer.

Atmospheric forcing was the main, but not the only cause. The location of the anticyclonic gyre, which in the last years displaced from the center of the Canadian Basin, influenced ice transport from the Chukchi, East Siberian, and Beauport seas. The intensity of this gyre increased and facilitated intensification of ice transport to the islands of the Canadian archipelago [2].

Analysis of the water mass volume was performed to estimate the changes in the water column. The analysis was based on all available deep oceanographic data in the summer seasons of 2007 and 1970-1979. In 1970-1979, low temperature of Atlantic waters was observed after a warm period in the 1940s and before the beginning of warming in the 1990s [6], which allows us to use this decade as a reference.

The weighted mean values of temperature and salinity were calculated for the entire volume of the Arctic Ocean analyzed here: in the summer of 2007, temperature and salinity values were $+1.2^{\circ} \mathrm{C}$ and $34.06 \%$, and in the 1970-1979 season, they were $+0.82^{\circ} \mathrm{C}$ and $34.25 \%$, respectively. It follows from these estimates that from the 1970s to the beginning of the next century, the waters of the Arctic Basin and adjacent Arctic seas became warmer by $0.38^{\circ} \mathrm{C}$ and their salinity decreased by $0.19 \%$.

Discrete functions of the distribution of water volumes as functions of temperature and salinity in 2007 and the summer seasons of 1970-1979 differ strongly (Figs. 1a, 1b; the water volume in meters per square unit is laid off as the ordinate). Variations in the thermohaline structure that occurred during the last 30 years are clearly seen in Fig. 1c, where the difference between distribution functions in 2007 and the summer seasons of 1970-1979 is shown. Vertical bars with white tops show positive anomalies of the water volume (water volumes of the given ranges of temperature and salinity are greater in 2007 than in 19701979). Vertical bars with black tops show negative anomalies of water volumes (water volumes of given gradations of temperature and salinity are smaller in 2007 than in 1970-1979).

Anomalous processes in the upper layer, which were discussed above, are reflected in the fact that the 
distribution function of anomalies has positive values in the temperature interval from $-0.4^{\circ} \mathrm{C}$ to $+1^{\circ} \mathrm{C}$ and salinity range less than $30.00 \%$.

Significant transformation of water volumes occurred in the following ranges of temperature and salinity: (0.0$\left.1.50^{\circ} \mathrm{C} ; 31.00-32.00 \% 0\right)$ and $\left(0.0-1.0^{\circ} \mathrm{C} ; 32.00-\right.$ $33.00 \%$ ). In 2007 , the water volume of the first range increased five times relative to the mean water volume with the same characteristics for the 1970-1979 decade. The main change occurred due to the increase in the volume of warm surface Barents Sea waters and summer Pacific waters. In 2007, the water volume of the second range decreased nine times in relative units.

In 2007, the total volume of Atlantic waters with temperature greater than $0^{\circ} \mathrm{C}$ and salinity greater than $34.6 \%$ increased by $22 \%$ relative to $1970-1979$. At the same time, variation in the partial water volumes in different temperature ranges occurred within the Atlantic water mass. For example, the volume of Atlantic waters with temperatures from $0^{\circ} \mathrm{C}$ to $2^{\circ} \mathrm{C}$ decreased, while the volume with temperatures greater than $2^{\circ} \mathrm{C}$ increased significantly. Such strong changes in the thermohaline structure of the Atlantic water layer were a sequence of increasing transport of warmer and less saline Atlantic waters to the Arctic Basin in the last two decades, especially after 20032004 [5].

The changes occurred also in deeper layers. In 2007, the volume of lower intermediate waters with temperatures from $-0.4^{\circ} \mathrm{C}$ to $0^{\circ} \mathrm{C}$ and salinities greater than $34.6 \%$ o decreased by $30 \%$. The underlying bottom waters became slightly warmer and less saline. Previously, it was found that the temperature of bottom waters increased after the increase in temperature of Atlantic waters in the Arctic Basin [7]. This regularity is confirmed by our analysis. It is not possible to estimate the volume of bottom waters in 2007 due to the limited number of measurements deeper than $1500 \mathrm{~m}$.
Our analysis demonstrates that significant changes in the thermohaline structure of the Arctic Ocean occurred in the last 30 years. Seasonal variations in the Arctic Ocean in 2007 were extreme, and variations in the intermediate layers and layer of the Atlantic waters were so significant that we have to put forward a problem about the limits of variations in the internal parameters of the Arctic oceanic system and evaluation of the probability of irreversible changes in the thermohaline structure and water and ice circulation in the Arctic Ocean. The problem of continuing monitoring in the Arctic Ocean becomes pressing due to possible consequences of the processes that occurred in the summer of 2007 as well as observed tendencies of significant variations in the thermohaline structure of the Arctic Ocean as a whole.

\section{REFERENCES}

1. I. E. Frolov, Z. M. Gudkovich, V. P. Karklin, et al., Scientific Studies in Arctics, vol. 2: Climate Changes of Ice Coating of Eurasian Shelf Seas (Nauka, St. Petersburg, 2007) [in Russian].

2. Review of Hydrometeorologic Processes in Arctic Ocean. 2007 Ed. by I. E. Frolov (Rotaprint GNTs RF AANII, St. Petersburg, 2008) [in Russian].

3. Z. M. Gudkovich, A. Yu. Proshutinsky, L. A. Timokhov, et al., in ACSYS Final Science Conf., 11-14 Nov., 2003, WCRP-118 (CD), WMO/TD No. 1232 (Sept., 2004).

4. T. J. Boyd, M. Steele, R. D. Muench, and J. T. Gunn, Geophys. Rev. Lett. 29, 1657 (2002).

5. I. V. Polyakov, A. Beszczynska, E. C. Carmack, et al., Geophys. Rev. Lett. 32, L17605 (2005).

6. I. V. Polyakov, G. V. Alekseev, L. A. Timokhov, et al., J. Clim., 4485-4497 (2004).

7. E. G. Nikiforov and A. O. Shpaikher, Regularities in. Forming Large-Scale Oscillations of the Hydrologic. Regime in the Arctic Ocean (Gidrometeoizdat, Leningrad, 1980) [in Russian]. 